\title{
Review Article \\ Clinical, MRI, and CSF Markers of Disability Progression in Multiple Sclerosis
}

\author{
Alberto Gajofatto, Massimiliano Calabrese, Maria Donata Benedetti, and Salvatore Monaco \\ Section of Clinical Neurology, Department of Neurological and Movement Sciences, University of Verona, Neurology Unit, Borgo Roma, \\ Azienda Ospedaliera Universitaria Integrata Verona, Piazzale Ludovico Antonio Scuro 9, 37134 Verona, Italy
}

Correspondence should be addressed to Alberto Gajofatto; alberto.gajofatto@gmail.com

Received 30 June 2013; Revised 12 September 2013; Accepted 9 October 2013

Academic Editor: Ralf Lichtinghagen

Copyright (C) 2013 Alberto Gajofatto et al. This is an open access article distributed under the Creative Commons Attribution License, which permits unrestricted use, distribution, and reproduction in any medium, provided the original work is properly cited.

\begin{abstract}
Multiple sclerosis (MS) is a chronic disorder of the central nervous system (CNS) in which the complex interplay between inflammation and neurodegeneration determines varying degrees of neurological disability. For this reason, it is very difficult to express an accurate prognosis based on purely clinical information in the individual patient at an early disease stage. Magnetic resonance imaging (MRI) and cerebrospinal fluid (CSF) biomarkers are promising sources of prognostic information with a good potential of quantitative measure, sensitivity, and reliability. However, a comprehensive MS outcome prediction model combining multiple parameters is still lacking. Current relevant literature addressing the topic of clinical, MRI, and CSF markers as predictors of MS disability progression is reviewed here.
\end{abstract}

\section{Introduction}

Multiple sclerosis (MS) is a chronic idiopathic disorder of the central nervous system (CNS) sustained by a multifocal inflammatory process predominantly affecting myelinsheathed axons. Although traditionally viewed as a white matter (WM) demyelinating disorder, MS is characterized by acute and chronic axonal and neuronal loss, as shown for long by pathological and neuroimaging studies $[1,2]$. Acute inflammation causes the development of plaques, characterized by blood-brain barrier (BBB) breakdown, perivascular cellular infiltration, demyelination, and axonal degeneration. Notably, axonal damage occurs not only in the acute phase but also in inactive MS lesions [3, 4]. Plaques represent the underlying pathological substrate of clinical events, with occurrence of focal/multifocal neurological symptoms and signs that eventually subside in many cases as inflammation ceases. Lesions may also involve the cortical gray matter (GM) in which case they are characterized by myelin/axonal injury and microglial activation but not BBB disruption [5] and less cellular infiltration compared to WM lesions $[6,7]$. It is increasingly perceived that the severity of MS clinical outcome does not simply result from the extent of
WM damage, but it rather represents a complex balance among WM and GM tissue damage, tissue repair, and cortical reorganisation [8-10]. The evidence that axonal loss highly correlates with neurological disability and disease progression [2] has spurred the search for reliable markers of axonal degeneration.

Although MS aetiology still remains undetermined, genetic and environmental risk factors have been identified or are suspected (i.e., female gender, HLA-DRB1 allele, genome-wide association studies candidate genes, EpsteinBarr virus infection, low vitamin D levels, cigarette smoking, etc.) mainly influencing immune system modulation andalthough much less evidently-myelin and axonal repair mechanisms [11-15]. The complex and unique interplay between genetic background and environmental exposure in each case likely determines the clinical heterogeneity of MSboth between and within subjects-varying from benign or even subclinical types to highly disabling forms and making it a challenge to predict the clinical course at the individual level. Given that MS is mostly diagnosed in subjects in the third and fourth decade of life, the availability of reliable predictors of long-term prognosis is extremely important. 
TABLE 1: Clinical markers of MS disability progression reported in longitudinal natural history studies.

\begin{tabular}{|c|c|c|}
\hline Marker & Findings & References \\
\hline Male gender & $\begin{array}{l}\text { Shorter time to walking assistance need (i.e., EDSS score 6) and/or } \\
\text { transition to the SP phase }\end{array}$ & [24-29] \\
\hline Older age & $\begin{array}{l}\text { Older age at onset associated with shorter time to EDSS } 6 \text { and/or to SP } \\
\text { phase }\end{array}$ & {$[24-28,30,31]$} \\
\hline Progressive course & $\begin{array}{l}\text { PP MS patients reach relevant disability milestones in a significantly } \\
\text { shorter time compared to RR MS cases }\end{array}$ & {$[24-27,30]$} \\
\hline Multifocal presentation & $\begin{array}{l}\text { Symptoms/signs of multiple CNS sites involvement at onset are } \\
\text { associated with shorter time to EDSS } 6 \text { and/or SP phase compared to } \\
\text { monofocal presentation }\end{array}$ & {$[27,30]$} \\
\hline Motor symptoms & $\begin{array}{l}\text { MS patients with pyramidal and/or cerebellar involvement at onset } \\
\text { reach EDSS } 6 \text { more rapidly compared to patients with optic nerve or } \\
\text { sensory symptoms (no influence on time to SP MS) }\end{array}$ & {$[24,25]$} \\
\hline Incomplete recovery & Shorter time to EDSS 6 and/or transition to the SP phase & {$[25,27,30]$} \\
\hline Relapse rate & $\begin{array}{l}\text { Shorter time to second attack and higher relapse number in first } 2-5 \\
\text { years after onset are associated with more rapid progression to EDSS } 6 \\
\text { and transition to the SP phase }\end{array}$ & {$[24,25,27,29,32]$} \\
\hline
\end{tabular}

EDSS: expanded disability status scale; PP: primary progressive; RR: relapsing remitting; SP: secondary progressive.

The objective of this paper is to review the current literature and to discuss evidence on clinical, paraclinical, magnetic resonance imaging (MRI), and cerebrospinal fluid (CSF) markers as predictors of disability progression in MS.

\section{Clinical and Paraclinical Markers of Disability Progression}

The typical clinical course of MS is relapsing-remitting (RR), characterized by an initial event of acute or subacute neurological disturbance, generally indicated as clinically isolated syndrome (CIS) followed by recurrence of symptoms over time. CIS is the type of onset in around $85 \%$ of MS cases, while the remaining $15 \%$ of patients have a progressive disease from onset (primary progressive (PP) MS) [16]. Progressive onset is an unfavourable prognostic predictor per se, since motor, sphincter control, and cognitive impairment are prominent features of the clinical picture, neurological disability continues to worsen over time, and no effective treatment exists [17]. Conversely, CISs generally recover well and may remain monophasic for a long time interval before conversion to clinically definite MS occurs. Since CIS represents the earlier clinical manifestation of RR MS, this patient population is of great value for identification of predictive and prognostic disease markers compared to definite MS cases who are necessarily in a more advanced stage. Typical CIS presentation includes acute partial myelitis (30-50\% of cases), brainstem/cerebellum syndromes (25-30\%) unilateral optic neuritis $(20-25 \%)$, and cerebral hemisphere syndromes (5\%); more than $20 \%$ of CISs present with symptoms and/or signs of more than one anatomical location (multifocal presentation) [18-20]. The percentage of CIS patients who develop clinically definite MS in prospective observational studies ranges from $16 \%$ at 1 year to $80 \%$ at 25 years $[21,22]$. However, these figures date back to studies conducted before the introduction of the most recent revision of MS diagnostic criteria according to which patients previously classified as CIS already have MS at the time of initial symptoms if MRI demonstrates space and time dissemination of demyelinating lesions [23].

After MS develops, irreversible disability may be the result of accumulation of fixed sequelae after each attack or may be due to transition to a secondary progressive (SP) phase, in which insidious neurological deterioration substitutes the preceding RR stage of the disease (32-58\% of cases in major prospective studies) [72]. Clinical predictors of long-term disability in MS include male gender, older age, multifocal symptoms, efferent systems involvement, incomplete remission of the initial event, a short interval to the second event, and high relapse rate in the first 2-5 years after onset, although not all studies replicated the same findings (Table 1) [24-27, 30, 31, 48, 73]. One single study reported a shorter time to secondary progressive MS in patients with family history of MS [74]. The relevance of age as a prognostic factor is subject to interpretation depending on the temporal frame in which disability levels are captured. Indeed, while older age at onset is associated with a more rapid disability progression-likely due to prevalence of the primary progressive disease course, age-dependent degenerative processes, and dysfunction of repair mechanisms in older subjectsearly onset MS patients reach disability milestones at a younger age compared to late onset MS cases, even though in a longer time interval $[26,75]$. This has been reported also in the paediatric population [76]. In addition, it has been shown that the progressive phase of MS is an age- rather than a disease duration-dependent process, since age at PP and SP MS onset overlaps significantly in large observational studies and subsequent disability progresses along a common agedriven trajectory independent of onset epoch and previous clinical course [77]. In this perspective, older age at onset may be viewed as a favourable prognostic factor, meaning a longer 
disease-free interval before MS symptoms occurrence in life and an older age at which significant disability milestones are reached, compared to early onset [72]. Also the influence of relapses on later disability progression is debated. According to the authors who found a positive correlation between relapses and long-term disability, the association is stronger in younger patients ( $<25$ years old at MS onset), it diminishes significantly after the first $2-5$ years of disease, and it is minimal after the progressive phase has begun $[32,78]$.

A sizable proportion of MS patients does not accumulate clinically relevant disability during the entire natural history of the disease. This type of course is known as benign MS, although there is no general agreement on its definition and consequently, on its prevalence in the MS population [79]. While initial definitions predominantly stressed the absence of significant ambulatory disability (expanded disability status scale (EDSS) score $<3.5$ or 2.5) [80] after a reasonable time interval from initial symptoms (10 or 15 years) [81, 82], more recent studies highlighted the importance of carefully considering cognitive status and quality of life when defining benign MS [83]. Indeed, EDSS, which is the most largely used disability scale in MS clinical practice, is clearly unbalanced towards ambulation impairment. Scores range from 0 meaning no disability to 10 meaning death due to MS: from score 1 to 3.5 , there can be a wide range of neurological deficit but ambulation is unrestricted; from 4 to 5.5 , independent ambulation is below 500 meters; from 6 to 7.5 , ambulation is only possible with support; and from 8 on, the patient is wheelchair-bound or bedridden.

Whatever the definition, it has been shown that benign status at 10 years after MS onset persist at 20 or more years in $52-69 \%$ of patients, leading to the conclusion that benign MS is a transient condition for a considerable proportion of cases $[82,84-86]$. However, studies addressing this topic are generally limited by the clinic-based design in which MS patients with mild disease who are not seen on a regular basis in the neurology practices are not included in the analysis falsely reducing the proportion of benign cases. There are no diagnostic tools or validated markers to identify MS patients who will have a favourable clinical course; however, female gender, younger age, and absence of motor symptoms at onset have been associated with a benign disease form [87].

Neurophysiological assessment with visual, somatosensory, motor, and brainstem auditory evoked potentials is traditionally used as a paraclinical tool for MS evaluation, although its diagnostic relevance has progressively decreased after MRI became largely available as a more sensitive technique. However, evoked potentials still maintain a prognostic significance likely because they reflect the functional integrity of specific anatomical pathways and consequently tend to better correlate with neurological disability than conventional MRI, which provide purely morphological information. Several cross-sectional and longitudinal studies established that the degree of evoked potentials abnormalities is significantly associated with the EDSS score at the time of neurophysiological evaluation and up to 14 years later in patients with MS [88-93]. A recent study found that CIS patients with at least three abnormal evoked potentials at baseline have an increased risk of reaching moderate disability over a mean follow-up period of six years, independent of initial MRI features [94].

In recent years optical coherence tomography (OCT) has emerged as a powerful tool to detect retinal nerve fiber layer (RNFL) thinning in MS patients with and without optic neuritis history [95]. RNFL thickness decrease results from axonal loss in optic nerve, possibly reflecting diffuse neuroaxonal injury in the CNS, and correlates with markers of MS activity such as relapses, new/gadolinium-enhancing lesions, and parenchymal atrophy on brain MRI $[96,97]$. The extent of RNFL thinning in optic neuritis patients predicts visual recovery and exhibits a modest correlation with overall neurological disability in MS patients. It has been recently suggested that thinning of inner and outer nuclear layers of the retina identifies a subset of MS patients with primary retinal neuronal pathology and more aggressive disease course $[98,99]$.

\section{MRI Markers of Disability Progression}

Given its increased availability and its sensitivity in detecting MS lesions, conventional MRI has become the main imaging tool in the MS diagnostic work up as well as in monitoring treatment response to disease-modifying drugs [100]. Its diagnostic sensitivity reflects the ability to identify clinically silent lesions, thus, favouring the early demonstration of dissemination in space and time of the lesions (Figure 1) according to the recent revision of diagnostic criteria [23].

However, while it may seem obvious that patients who develop new WM lesions are worse off than those without new lesions, conventional MRI has been shown to have a prognostic value only in patients at disease onset: high T2-weighted lesion load in patients with a CIS has been associated with an increased risk of subsequent conversion to clinically definite MS and long-term disability accumulation $[101,102]$. By contrast, in a more advanced phase of the disease, the strength of relationship between conventional MRI measures and subsequent disability progression is rather weak $[33,34]$. In a recent study including 548 placebo-treated RR MS patients, the multivariate analysis indicated just EDSS score and T2 lesion load as factors independently predicting the clinical progression. Nevertheless, these two variables taken together were able to account for only $3 \%$ of the probability to have an EDSS increase over follow-up time, thus, confirming the limited value of these metrics in predicting short-term disability changes in RR MS [35]. Such result is in line with those of several previous cross-sectional and longitudinal studies conducted on smaller groups of patients with different clinical characteristics, which have shown only modest correlation between T2- and T1-weighted brain MRI activity and subsequent changes in disability [36-38].

Although EDSS is not without limitations in terms of reliability and responsiveness to disease changes, the lack of a strong correlation between WM lesion load and clinical disability had prompted investigations of the so-called normalappearing brain tissue. For this purpose, unconventional and quantitative MRI techniques, having increased sensitivity and specificity to irreversible tissue damage, have been consistently applied to monitor and predict MS evolution. 


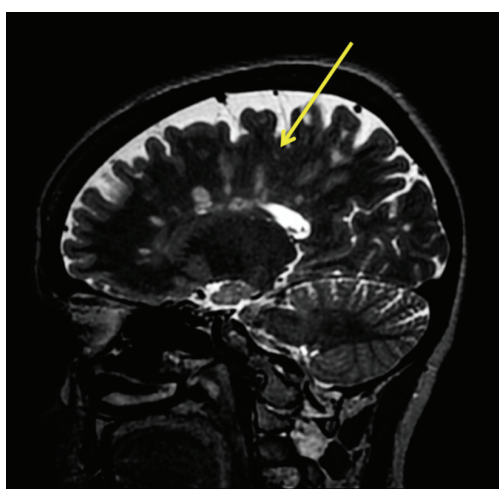

(a)

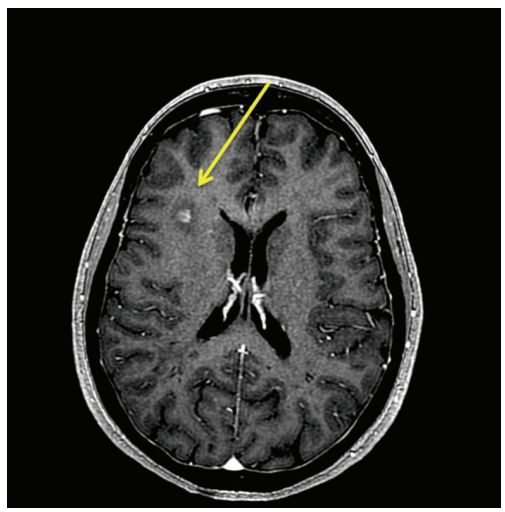

(d)

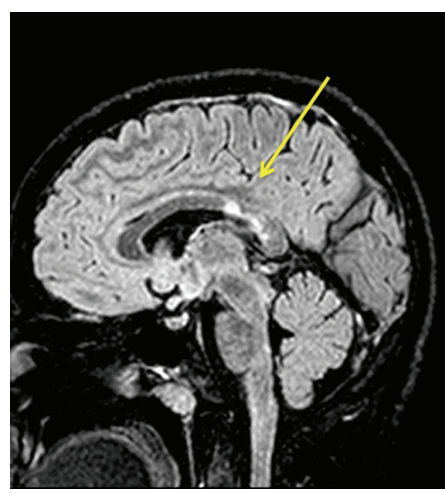

(b)

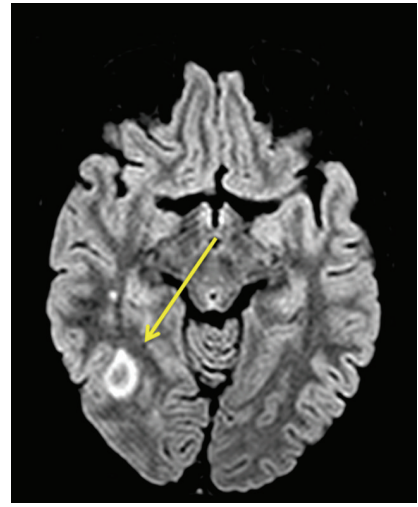

(e)

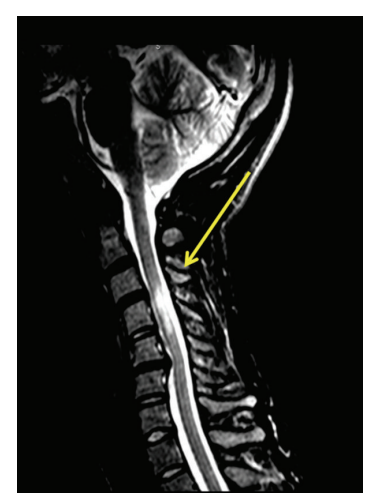

(c)

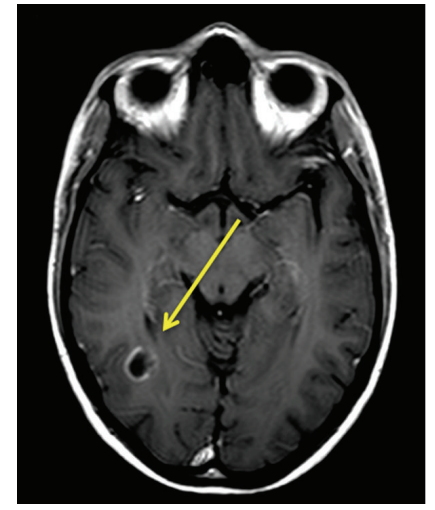

(f)

FIGURE 1: Different types of white matter lesions in MS. (a) Periventricular lesions (Dawson's fingers); (b) lesions in the corpus callosum; (c) spinal cord lesion; (d) active lesion; and (e, f) reactivated lesion with classical "ring" contrast enhancement (f).

Given these premises, several studies have been focused on brain atrophy showing its relevant clinical impact not only in the diagnostic phase [103] but also in predicting subsequent disability progression both in RR MS [39] and in PP MS [40] (Figure 2). A recent study published by the MAGNIMS group, included $261 \mathrm{MS}$ patients who had MR imaging at baseline and after 1-2 years and EDSS scoring at baseline and after 10 years; in the whole patient group, after correction for imaging protocol, whole brain and central atrophy were good predictors of EDSS at 10 years $\left(R^{2}=0.74\right)[41]$.

Despite the good sensitivity of brain atrophy, even better results in predicting disability progression have been further achieved by the regional analysis of brain atrophy. Jasperse and colleagues, for example, suggested that atrophy of central brain regions was related to decline in ambulatory function, whereas atrophy of both central and peripheral brain regions was associated to decline in neurologically more complex tasks for coordinated hand function [42].

The best results, however, have been obtained by the study of GM and WM atrophy separately. Indeed several voxelbased and surface-based studies, both in RRMS and in PPMS, revealed strong relationship between GM, but not WM, atrophy and disability progression [43-45]. Even when a very long followup, a very large sample size, or more sophisticated disability scales (i.e., MS Functional Composite) were considered, GM atrophy reflected disease subtype and disability progression to a greater extent than WM atrophy or lesions [45-47].

A further step forward in the comprehension of the pathological mechanisms underlying the accumulation of irreversible disability in MS was obtained by the regional analysis of GM atrophy; since the first studies, indeed, it was clear that some cortical and deep GM structures were more prone to inflammatory and degenerative damage [49, 50] than others and that, when damaged, some cortical areas had a greater impact on the accumulation of physical $[8,51]$ and cognitive disability $[52,53]$ than others. In particular thalamus and cerebellum were consistently related to clinical disability and its progression over time. Thalamus was found to be one of the earliest structures involved by the neuropathological process taking place in the GM and the rate of thalamic atrophy in MS subjects was correlated with changes in EDSS [50]. Moreover, in a longitudinal study, baseline thalamic fraction (odds ratio $=0.62$ ) was identified as independent predictor of worsening disability at 8 years [104]. Cerebellum has been indicated as a preferred site of demyelination, especially in patients with progressive MS, whose cerebellar cortex was found to be affected by MSrelated pathology in up to $92 \%$ of its extension $[105,106]$. In a recent 5-year longitudinal study cerebellar cortical atrophy, together with age and cortical lesion load, was indicated 


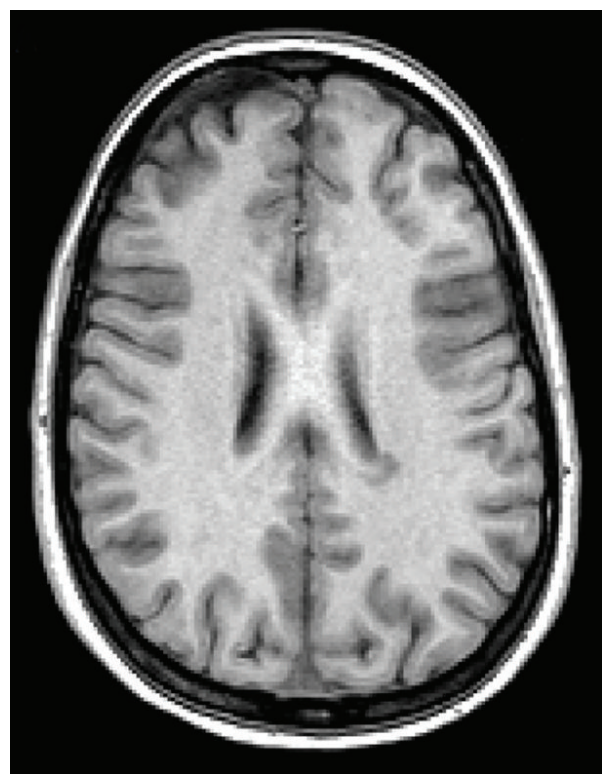

(a)

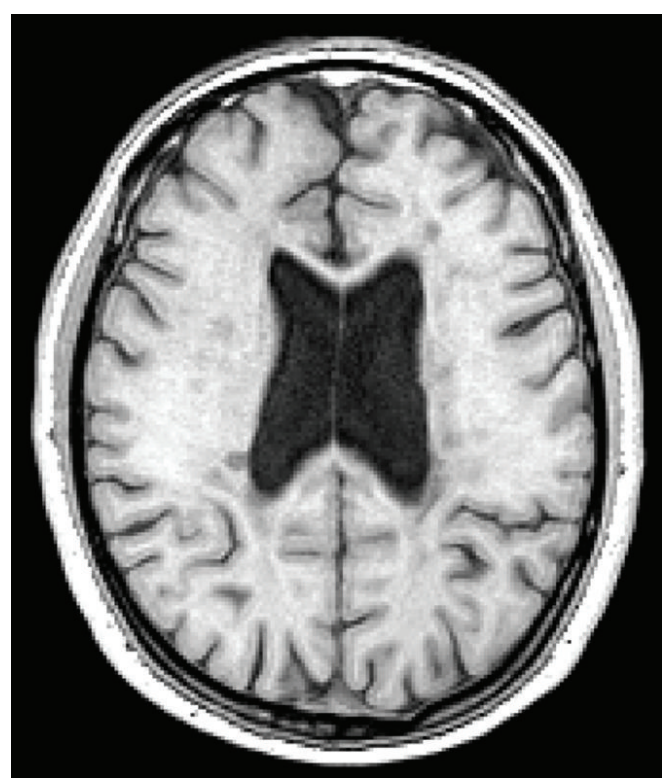

(b)

FIGURE 2: Axial volumetric T1 weighted images of a relapsing-remitting (RR) MS patient with EDSS = 1.5 (a) and of a secondary progressive (SP) MS patient with EDSS $=5.5$ (b). The SP patient showed significant whole brain and grey matter atrophy compared to RR patient.

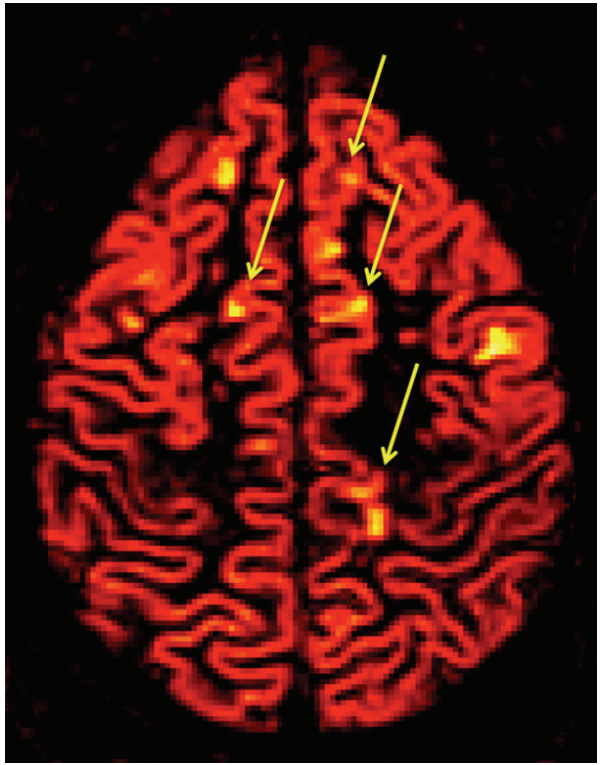

(a)

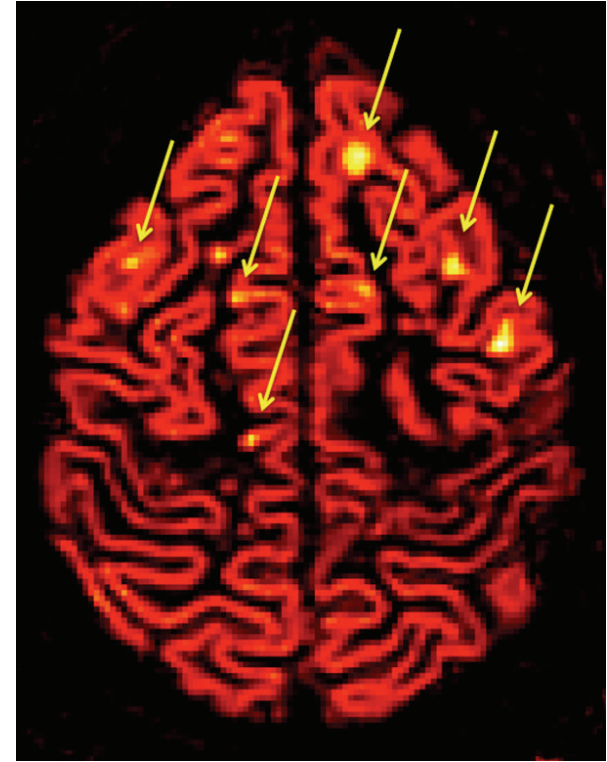

(b)

FIgURE 3: Two contiguous red coloured axial brain MRI scans acquired with double inversion recovery sequence in a relapsing-remitting MS patient. Several intracortical lesions have been identified (arrows).

among the predictive parameters of progression in those RR MS patients who convert to the SP phase [48].

Beyond diffuse GM damage, the relevance of cortical damage in determining disability has been pointed out by the strong correlation observed between focal GM damage as visible by double inversion recovery (DIR) sequence (i.e., cortical lesions; Figure 3) and clinical progression. Indeed, high number of cortical lesions has been demonstrated to characterize patients with the poorest prognosis and having early and severe cortical atrophy and cognitive impairment [107]. In a 5-year longitudinal study on more than $300 \mathrm{MS}$ patients with different clinical phenotypes, cortical lesion volume and GM atrophy were found to be associated to each other and to physical and cognitive disability progressions. Patients having high cortical lesion load at baseline showed the worse clinical evolution and a significant progression of 
cortical atrophy after 5 years. This was observed in all clinical subsets [54].

Of course a complete and accurate evaluation of the risk of clinical progression should not disregard the evaluation of spinal cord damage that has suggested as a major determinant of disability in patients with MS [55]. In line with what has been happened for the brain damage, the application of quantitative MRI techniques to the spinal cord damage has convincingly demonstrated that cord area, rather than T2 lesion load, might have a role in predicting the accumulation of disability $[56,57,108]$.

In the last 10 years, finally, other non-conventional sequences have received considerable attention since their high sensitivity for the most disabling pathological features of MS (i.e., irreversible demyelination and neuroaxonal injury) and their ability to detect "occult" changes occurring in the normal-appearing brain tissue. Among these unconventional techniques magnetization transfer and diffusion tensor imaging gave the most interesting results. In 73 patients, who were followed prospectively with clinical visits for a median period of 8 years, a multivariable model identified baseline GM magnetization transfer ratio histogram peak height and average lesion magnetization transfer ratio percentage change after 12 months as independent predictors of disability worsening at 8 years $\left(r^{2}=0.28\right)$ [58]. In a longitudinal study on 54 primary progressive MS patients, lower level of disability and GM damage evaluated at study entry on the base of average GM mean diffusivity identified patients with high risk of disease progression over the following 5 years [59]. In a more recent prospective study fractional anisotropy of normal appearing GM and T2 lesion load were independent predictors of EDSS score, while change in fractional anisotropy of normal appearing $\mathrm{GM}(B=0.523)$ and disease duration $(B=0.342)$ were independent predictors of EDSS change [60]. Finally, the application of diffusion tensor imaging to the spinal cord damage revealed that baseline cord cross-sectional area and its fractional anisotropy correlated with increase in disability at follow-up [109].

All together these studies confirmed that neurological and neuropsychological disability in MS are likely the consequence of both visible and invisible WM and GM damage. The strength of correlation between GM tissue loss and progression of disability exceeds that related to WM lesions or atrophy (Table 2). Unfortunately, GM damage is poorly evaluated by conventional MRI and to achieve more accurate estimates of such a damage it requires multiparametric MRI approach including unconventional and quantitative MRI techniques, many of which are not yet available or practicable in routine diagnostics.

\section{CSF Markers of Progression}

The examination of CSF represents a valuable procedure in investigating a number of inflammatory and degenerative neurological disorders. In addition to the classical biochemical and electrophoretic approaches, the proteome complexity of CSF can be tackled today by a number of methods, hence, indicating that scientists involved in this frontier are fishing in the right pond. However, in a disorder with a complex pathogenesis, such as MS, individual biomarkers, taken singly, are likely to reflect only isolated components of ongoing neuroinflammation and neurodegeneration, hence, lacking prognostic significance. Moreover, most of the investigated MS biomarkers, while of invaluable diagnostic help, are currently unsuitable for predicting disease progression.

According to their biological role, molecules of potential prognostic significance for MS may be classified as follows: (i) markers of immune activation (e.g., cytokines, chemokines, antibodies, complement factors, adhesion molecules, etc.); (ii) markers of blood-brain barrier disruption (e.g., matrix metalloproteinases); (iii) markers of demyelination (e.g., myelin basic protein, myelin oligodendrocyte glycoprotein, proteolytic enzymes, proteases inhibitors, etc.); (iv) markers of oxidative stress and cytotoxicity (e.g., advanced oxidation protein products, total thiol, hydroxyl radicals, divalent iron, etc.); (v) markers of axonal/neuronal damage and gliosis (e.g., neurofilaments, tau, 14-3-3 protein, glial fibrillary acidic protein, etc.); and (vi) markers of remyelination/neural repair (e.g., nerve growth factor, brain-derived growth factor, NogoA, etc.).

A correlation with MS disability progression over time has been suggested for several CSF markers, including but not limited to 14-3-3 protein [61]; tau [110]; neurofilament heavy chain $[66,67]$; chitinase 3 -like 1 [70]; and cystatin C [71]. CSF IgG oligoclonal bands, which have a recognized relevance for the diagnosis of MS and predict conversion from CIS to MS, do not influence the long-term risk of disability, although a contrasting observation has been described [63]. Conversely, CSF oligoclonal IgM, particularly if directed against myelin lipids, have been associated with a poor MS outcome in terms of frequency of relapses and disability progression $[68,69]$. Several CSF markers of inflammation have been investigated for potential prognostic value in CIS and early MS patients. Some studies have identified novel biological predictors of conversion from CIS to MS, for instance measles-rubellavaricella zoster virus IgG antibody reaction (MRZR) and high levels of C-X-C motif ligand 13 (CXCL13) and in the CSF. However, no predictive value for progression of disability has been shown for such molecular candidates [111, 112].

Since neurodegeneration is regarded as the biological determinant of irreversible neurological disability in demyelinating disorders, CSF markers of neuroaxonal injury (e.g., tau, 14-3-3 protein, and neurofilaments) are the most promising candidates for predicting disease progression $[113,114]$. CSF tau concentration in MS patients with both relapsing and progressive forms of the disease has been reported to be higher compared to controls in several studies [110, 115119], although other researchers did not replicate this finding [120-122]. A correlation between CSF tau and progression of disability in MS patients has been shown only in one 3-year follow-up study [110]. In a small group of patients with CIS and clinically definite MS, investigated either at the acute attack (i.e., within 30 days) or several weeks or months later, our group found values of tau within normal limits [123], a finding that we later confirmed in a larger mostly independent cohort of CIS patients [73]. Interestingly, it has been shown that CSF tau levels decrease during the course of 
TABLE 2: MRI markers.

\begin{tabular}{|c|c|c|c|}
\hline Marker & Disease phase & Findings & References \\
\hline \multirow{2}{*}{ T2 lesion load } & CIS & Good association with conversion to definite MS & \multirow{2}{*}{ [33-37] } \\
\hline & Later in the RR phase & Weak association with disability (EDSS) progression & \\
\hline T1 lesion load & $\mathrm{RR}$ & $\begin{array}{l}\text { The change in } \mathrm{T} 1 \text { lesion volume correlated more } \\
\text { strongly with disability progression than did } \mathrm{T} 2 \text { lesion } \\
\text { volume change }\end{array}$ & {$[38]$} \\
\hline Brain atrophy & CIS, early RR, and PP & $\begin{array}{l}\text { Whole brain and central atrophy were good predictors } \\
\text { of EDSS at } 10 \text { years }\left(R^{2}=0.74\right)\end{array}$ & [39-42] \\
\hline GM atrophy & Early RR and PP & $\begin{array}{l}\text { Good relationship with disability progression } \\
\text { (definitely better than WM atrophy) }\end{array}$ & {$[43-47]$} \\
\hline Regional GM atrophy & $\mathrm{CIS}, \mathrm{RR}$, and PP & $\begin{array}{l}\text { Good correlation with disability progression and } \\
\text { cognitive dysfunction: rate of thalamic atrophy in MS } \\
\text { subjects was correlated with changes in EDSS; } \\
\text { cerebellar cortical atrophy was indicated among the } \\
\text { predictive parameters of progression in those RR MS } \\
\text { patients who converted to the SP phase }\end{array}$ & {$[48-53]$} \\
\hline GM lesion load & Early and long-standing RR & $\begin{array}{l}\text { Good association with GM atrophy and progression of } \\
\text { physical and cognitive disability }\end{array}$ & {$[54]$} \\
\hline Spinal cord area & CIS and early RR & $\begin{array}{l}\text { Cord area, rather than } \mathrm{T} 2 \text { lesion load, might have a role } \\
\text { in predicting the accumulation of disability }\end{array}$ & [55-57] \\
\hline $\begin{array}{l}\text { GM magnetization transfer } \\
\text { ratio }\end{array}$ & CIS, RR, and SP & $\begin{array}{l}\text { GM magnetization transfer ratio histogram peak height } \\
\text { and average lesion magnetization transfer ratio } \\
\text { percentage change after } 12 \text { months were independent } \\
\text { predictors of disability worsening at } 8 \text { years }\left(R^{2}=0.28\right)\end{array}$ & {$[58]$} \\
\hline $\begin{array}{l}\text { GM mean diffusivity and } \\
\text { fractional anisotropy }\end{array}$ & $\mathrm{RR}$ and $\mathrm{PP}$ & $\begin{array}{l}\text { Average GM mean diffusivity, identified patients with } \\
\text { high risk of disease progression over the following } 5 \\
\text { years; change in fractional anisotropy of normal } \\
\text { appearing GM }(B=0.523) \text { and disease duration } \\
(B=0.342) \text { were independent predictors of EDSS } \\
\text { change }\end{array}$ & {$[59,60]$} \\
\hline
\end{tabular}

CIS: clinically isolated syndrome; EDSS: expanded disability status scale; GM: grey matter; PP: primary progressive; RR: relapsing remitting; SP: secondary progressive; WM: white matter.

MS, as a likely effect of progressive parenchymal brain loss, hence, showing a negative correlation with clinical severity [124]. The latter findings are consistent with studies showing progressive brain atrophy in MS patients, regardless of disease subtype [125]. Taken together, while the determination of CSF tau concentration in MS deserves further scrutiny, it is possible that in a subset of MS patients, this protein represent a reliable marker of axonal injury. Conversely, available evidence shows that determination of $\mathrm{p}$-tau has no value as a biomarker.

14-3-3 protein has also been detected in the CSF of subjects with CIS/MS by several $[61,62,116,126,127]$ but not all research groups [119]. Martínez-Yélamos et al. showed that a positive CSF 14-3-3 assay at the first neurological event suggestive of MS predicted the development of significant neurological disability over a median follow-up period of 32 months [61], while Colucci et al. found that 14-3-3 positive MS patients had a higher rate of EDSS progression over 10 months compared to 14-3-3 negative cases [62]. Fiorini et al. found variable upregulation of CSF $14-3-3 \beta / \zeta$ in CIS/MS patients investigated at active or inactive disease stages (as observed in other inflammatory/demyelinating conditions) but not overexpression of 14-3-3 $\gamma$ and $\varepsilon$, the isoforms typical of disorders characterized by ongoing axonal and neuronal degeneration, such as sporadic Creutzfeldt-Jakob disease (sCJD) and motor neuron disease [123]. These findings encourage an in-dept-analysis in larger cohorts of patients, before ruling out the usefulness of this biomarker.

Among CSF biomarkers of neurodegeneration that have been tested in MS, neurofilaments seem to stand out for potential prognostic value. Neurofilament heavy and light chain proteins (NFH and NFL, resp.) concentrations are increased in the CSF of MS patients compared to agematched normal controls. Furthermore, CSF NFL levels seem to better correlate with MS acute inflammatory activity (higher levels in CIS patients who convert to MS and during relapse compared to remission phase), while CSF NFH concentrations appear to be related to irreversible neuroaxonal 
TABLE 3: CSF markers of MS disability progression reported in longitudinal studies.

\begin{tabular}{|c|c|c|}
\hline Marker & Findings & References \\
\hline \multirow[t]{2}{*}{$14-3-3$ protein } & $\begin{array}{l}14-3-3 \text { positive CIS patients group reached more frequently EDSS } \geq 2.0 \text { at the end } \\
\text { of the } 32 \text { months follow-up period compared to } 14-3-3 \text { negative CIS cases }(57 \% \\
\text { versus } 20.5 \% ; P=0.05)\end{array}$ & {$[61]$} \\
\hline & $\begin{array}{l}\text { 14-3-3 positive patients had higher EDSS progression rate over } 8.5 \text { months } \\
\text { following lumbar puncture }\end{array}$ & {$[62]$} \\
\hline Tau & $\begin{array}{l}\text { RR MS patients with higher CSF tau experienced a more rapid one point increase } \\
\text { in the EDSS score during a mean followup of } 3 \text { years }\end{array}$ & {$[63]$} \\
\hline \multirow[t]{2}{*}{ NFL } & $\begin{array}{l}\text { Significant correlation between CSF NFL levels } \\
\text { and EDSS progression over } 10 \text { years }\end{array}$ & {$[64]$} \\
\hline & $\begin{array}{l}\text { Higher multiple sclerosis severity score and higher rate of conversion from } \\
\text { RRMS to SPMS at } 14 \text { years followup in cases with high CSF NFL levels compared } \\
\text { to those with undetectable or intermediate NFL levels }\end{array}$ & {$[65]$} \\
\hline \multirow[t]{2}{*}{ NFH } & $\begin{array}{l}\text { Correlation with EDSS at } 3 \text { years followup in relapsing and progressive MS } \\
\text { patients }(R=0.54 ; P<0.01)\end{array}$ & {$[66]$} \\
\hline & Correlation with EDSS score $6-8$ weeks after relapse onset $(R=0.46 ; P=0.04)$ & {$[67]$} \\
\hline \multirow[t]{2}{*}{$\operatorname{IgM} \mathrm{OB}$} & $\begin{array}{l}\text { MS patients with positive IgM OB recognizing myelin lipids reached higher } \\
\text { disability compared to cases with positive IgM OB not-recognizing myelin lipids } \\
\text { over a mean follow-up time of } 61 \text { months (mean EDSS score } 2.2 \pm 0.2 \text { versus } \\
1.2 \pm 0.2 ; P=0.02 \text { ) }\end{array}$ & {$[68]$} \\
\hline & $\begin{array}{l}\text { Positive IgM OB were an independent predictor of the probability of reaching } \\
\text { EDSS score } 3 \text { or } 4 \text { in RR MS patients at } 5 \text { and } 10 \text { years followup endpoints }\end{array}$ & {$[69]$} \\
\hline Chitinase3-like1 & $\begin{array}{l}\text { High levels were associated with disability progression during followup in CIS } \\
\text { patients who converted to MS }\end{array}$ & {$[70]$} \\
\hline Cystatin C & $\begin{array}{l}\text { Correlation with EDSS score at last visit (median followup }=6 \text { years) in patients } \\
\text { with recurrent myelitis and spinal onset MS (rho }=0.69 ; P=0.03 \text { ) }\end{array}$ & {$[71]$} \\
\hline
\end{tabular}

CIS: clinically isolated syndrome; NFH: neurofilament heavy chain; NFL: neurofilament light chain; OB: oligoclonal bands.

injury as indicated by the correlation with confirmed EDSS score progression and brain atrophy both in cross-sectional and longitudinal studies $[64,65,122,128-130]$.

Table 3 shows CSF markers for which a correlation with MS disability progression has been reported in longitudinal studies.

\section{Conclusive Remarks}

Complexity and heterogeneity are the clinical and pathogenetic hallmarks of MS. After diagnosis, which is not straightforward in all cases, clinicians have to be prepared for the challenge of prognostic predictions in order to give adequate responses to patients concern about their future life with MS. Among the determinants of MS burden, development of irreversible neurological disability, particularly when affecting motor and cognitive functions, has the highest impact on patients quality of life and health system costs. Therefore, prognostic markers of long-term disability progression are strongly needed in MS.

A prognostic marker is a specific parameter or a combination of parameters that can be measured in a subject with a given condition and that is significantly correlated with a relevant clinical outcome of that condition. Ideally, reliable prognostic marker studies should fulfil the following methodological requirements: (1) prospective or longitudinal design; (2) long-term followup; (3) adequate marker and outcome measurement; (4) clinical significance of the marker (i.e., good correlation and consistency with relevant clinical outcomes); and (5) reproducibility [131].

Clinical prognostic markers that are associated with an increased risk of disability progression in the longterm (e.g., male gender, older age, progressive onset, etc.) have been identified in several MS natural history studies. However, besides identifying subjects who are more likely to experience a severe disease course, such markers do not offer real advantages in terms of prediction potential, since they are not modifiable risk factors, do not directly reflect biological processes, and do not generally distinguish between responders and nonresponders to available MS treatments.

Conversely, MRI and CSF parameters, which can be classified as biomarkers as they express more closely biological mechanisms underlying the disease pathophysiology, have a good potential of quantitative assessment as well as variation according to disease stage. Considering the complex pathogenesis of MS, however, no single biomarker is expected to have absolute prognostic significance. However, families of biomarkers representative of specific pathogenetic pathways-particularly those related to axonal/neuronal 
damage-may correlate with irreversible neurological dysfunction and be used as prognostic indicators to identify patients at risk of a more aggressive disease course. Furthermore, such a biomarker might be helpful for identifying patients who could benefit from therapy in case it showed a reliable correlation with the response to a given treatment. Unfortunately, no conventional MRI measure has shown strong correlation with long-term disability progression in MS, while unconventional MRI techniques-particularly those assessing GM damage-are currently being investigated with promising results, although they are still difficult to apply in clinical settings. On the other hand, research on CSF biomarkers has gathered convincing preliminary evidence only for NFH and NFL as predictors of disability progression. So far, biomarkers studies have mainly focused on selected candidates and have generally recruited relatively small sample of cases with a cross-sectional design, often showing conflicting results. It is likely that discrepancies across studies are at least in part explained by differences in selection of patients, marker measurement, and outcome assessment. Although a considerable level of international agreement has been reached on methodological requirements of MRI studies in MS, an effort is being made by the CSF markers research community in order to standardize collection and biobanking of samples from well clinically characterized MS patients to develop reproducible laboratory assays for CSF analysis and to find common definitions of healthy and diseased controls $[132,133]$.

To identify reliable prognostic markers, future MS research will need to focus on large longitudinal observational studies and clinical trials exploring the correlation of unconventional MRI measures and selected CSF proteins with the development of irreversible neurological disability.

\section{References}

[1] B. D. Trapp, J. Peterson, R. M. Ransohoff, R. Rudick, S. Mörk, and L. Bö, "Axonal transection in the lesions of multiple sclerosis," The New England Journal of Medicine, vol. 338, no. 5, pp. 278-285, 1998.

[2] J. H. van Waesberghe, W. Kamphorst, C. J. de Groot et al., "Axonal loss in multiple sclerosis lesions: magnetic resonance imaging insights into substrates of disability," Annals of Neurology, vol. 46, no. 5, pp. 747-754, 1999.

[3] B. Ferguson, M. K. Matyszak, M. M. Esiri, and V. H. Perry, "Axonal damage in acute multiple sclerosis lesions," Brain, vol. 120, no. 3, pp. 393-399, 1997.

[4] D. Barnes, P. M. G. Munro, B. D. Youl, J. W. Prineas, and W. I. McDonald, "The longstanding MS lesion. A quantitative MRI and electron microscopic study," Brain, vol. 114, no. 3, pp. 12711280, 1991.

[5] J. van Horssen, B. P. Brink, H. E. de Vries, P. Van der Valk, and L. Bø, "The blood-brain barrier in cortical multiple sclerosis lesions," Journal of Neuropathology and Experimental Neurology, vol. 66, no. 4, pp. 321-328, 2007.

[6] J. W. Peterson, L. Bö, S. Mörk, A. Chang, and B. D. Trapp, “Transected neurites, apoptotic neurons, and reduced inflammation in cortical multiple sclerosis lesions," Annals of Neurology, vol. 50, no. 3, pp. 389-400, 2001.
[7] C. F. Lucchinetti, B. F. G. Popescu, R. F. Bunyan et al., "Inflammatory cortical demyelination in early multiple sclerosis," The New England Journal of Medicine, vol. 365, no. 23, pp. 2188-2197, 2011.

[8] A. Charil, A. Dagher, J. P. Lerch, A. P. Zijdenbos, K. J. Worsley, and A. C. Evans, "Focal cortical atrophy in multiple sclerosis: relation to lesion load and disability," NeuroImage, vol. 34, no. 2, pp. 509-517, 2007.

[9] R. Reynolds, F. Roncaroli, R. Nicholas, B. Radotra, D. Gveric, and O. Howell, "The neuropathological basis of clinical progression in multiple sclerosis," Acta Neuropathologica, vol. 122, no. 2, pp. 155-170, 2011.

[10] J. J. Geurts, M. Calabrese, E. Fisher, and R. A. Rudick, "Measurement and clinical effect of grey matter pathology in multiple sclerosis," The Lancet Neurology, vol. 11, no. 12, pp. 1082-1192, 2012.

[11] S. Sawcer, "The complex genetics of multiple sclerosis: pitfalls and prospects," Brain, vol. 131, no. 12, pp. 3118-3131, 2008.

[12] International Multiple Sclerosis Genetics Consortium, "MANBA, CXCR5, SOX8, RPS6KB1 and ZBTB46 are genetic risk loci for multiple sclerosis," Brain, vol. 136, no. 6, pp. 1778-1782, 2013.

[13] A. Ascherio and K. L. Munger, "Environmental risk factors for multiple sclerosis. Part I: the role of infection," Annals of Neurology, vol. 61, no. 4, pp. 288-299, 2007.

[14] A. Ascherio and K. L. Munger, "Environmental risk factors for multiple sclerosis. Part II: noninfectious factors," Annals of Neurology, vol. 61, no. 6, pp. 504-513, 2007.

[15] A. Nylander and D. A. Hafler, "Multiple sclerosis," Journal of Clinical Investigation, vol. 122, no. 4, pp. 1180-1188, 2012.

[16] C. Confavreux and S. Vukusic, "Natural history of multiple sclerosis: a unifying concept," Brain, vol. 129, no. 3, pp. 606-616, 2006.

[17] D. H. Miller and S. M. Leary, "Primary-progressive multiple sclerosis," The Lancet Neurology, vol. 6, no. 10, pp. 903-912, 2007.

[18] C. Confavreux, S. Vukusic, T. Moreau, and P. Adeleine, "Relapses and progression of disability in multiple sclerosis," The New England Journal of Medicine, vol. 343, no. 20, pp. 1430$1438,2000$.

[19] M. Tintoré, A. Rovira, J. Rio et al., "Is optic neuritis more benign than other first attacks in multiple sclerosis?" Annals of Neurology, vol. 57, no. 2, pp. 210-215, 2005.

[20] E. M. Mowry, S. Deen, I. Malikova, J. Pelletier, P. Bacchetti, and E. Waubant, "The onset location of multiple sclerosis predicts the location of subsequent relapses," Journal of Neurology, Neurosurgery and Psychiatry, vol. 80, no. 4, pp. 400-403, 2009.

[21] M. P. Sormani, M. Tintorè, M. Rovaris et al., "Will Rogers phenomenon in multiple sclerosis," Annals of Neurology, vol. 64, no. 4, pp. 428-433, 2008.

[22] M. Eriksson, O. Andersen, and B. Runmarker, "Long-term follow up of patients with clinically isolated syndromes, relapsingremitting and secondary progressive multiple sclerosis," Multiple Sclerosis, vol. 9, no. 3, pp. 260-274, 2003.

[23] C. H. Polman, S. C. Reingold, B. Banwell et al., "Diagnostic criteria for multiple sclerosis: 2010 revisions to the McDonald criteria," Annals of Neurology, vol. 69, no. 2, pp. 292-302, 2011.

[24] B. G. Weinshenker, G. P. A. Rice, J. H. Noseworthy, W. Carriere, J. Baskerville, and G. C. Ebers, "The natural history of multiple sclerosis: a geographically based study. 3. Multivariate analysis of predictive factors and models of outcome," Brain, vol. 114, no. 2, pp. 1045-1056, 1991. 
[25] C. Confavreux, S. Vukusic, and P. Adeleine, "Early clinical predictors and progression of irreversible disability in multiple sclerosis: an amnesic process," Brain, vol. 126, no. 4, pp. 770-782, 2003.

[26] H. Tremlett, D. Paty, and V. Devonshire, "Disability progression in multiple sclerosis is slower than previously reported," Neurology, vol. 66, no. 2, pp. 172-177, 2006.

[27] M. Debouverie, S. Pittion-Vouyovitch, S. Louis, and F. Guillemin, "Natural history of multiple sclerosis in a population-based cohort," European Journal of Neurology, vol. 15, no. 9, pp. 916-921, 2008.

[28] H. Tremlett, Y. Zhao, and V. Devonshire, "Natural history of secondary-progressive multiple sclerosis," Multiple Sclerosis, vol. 14, no. 3, pp. 314-324, 2008.

[29] S. Vukusic and C. Confavreux, "Prognostic factors for progression of disability in the secondary progressive phase of multiple sclerosis," Journal of the Neurological Sciences, vol. 206, no. 2, pp. 135-137, 2003.

[30] B. Runmarker and O. Andersen, "Prognostic factors in a multiple sclerosis incidence cohort with twenty-five years of follow-up," Brain, vol. 116, no. 1, pp. 117-134, 1993.

[31] M. W. Koch, M. Uyttenboogaart, A. van Harten, and J. de Keyser, "Factors associated with the risk of secondary progression in multiple sclerosis," Multiple Sclerosis, vol. 14, no. 6, pp. 799-803, 2008.

[32] H. Tremlett, M. Yousefi, V. Devonshire, P. Rieckmann, and Y. Zhao, "Impact of multiple sclerosis relapses on progression diminishes with time," Neurology, vol. 73, no. 20, pp. 1616-1623, 2009.

[33] M. Filippi, D. W. Paty, L. Kappos et al., "Correlations between changes in disability and T2-weighted brain MRI activity in multiple sclerosis: a follow-up study," Neurology, vol. 45, no. 2, pp. 255-260, 1995.

[34] L. Kappos, D. Moeri, E. W. Radue et al., "Predictive value of gadolinium-enhanced magnetic resonance imaging for relapse rate and changes in disability or impairment in multiple sclerosis: a meta-analysis," The Lancet, vol. 353, no. 9157, pp. 964-969, 1999.

[35] S. Mesaros, M. A. Rocca, M. P. Sormani, A. Charil, G. Comi, and M. Filippi, "Clinical and conventional MRI predictors of disability and brain atrophy accumulation in RRMS: a large scale, short-term follow-up study, Journal of Neurology, vol. 255, no. 9, pp. 1378-1383, 2008.

[36] S. A. Gauthier, M. Mandel, C. R. G. Guttmann et al., "Predicting short-term disability in multiple sclerosis," Neurology, vol. 68, no. 24, pp. 2059-2065, 2007.

[37] V. L. Stevenson, G. T. Ingle, D. H. Miller, and A. J. Thompson, "Magnetic resonance imaging predictors of disability in primary progressive multiple sclerosis: a 5-year study," Multiple Sclerosis, vol. 10, no. 4, pp. 398-401, 2004.

[38] M. Sailer, N. A. Losseff, L. Wang, M. L. Gawne-Cain, A. J. Thompson, and D. H. Miller, "T1 lesion load and cerebral atrophy as a marker for clinical progression in patients with multiple sclerosis. A prospective 18 months follow-up study," European Journal of Neurology, vol. 8, no. 1, pp. 37-42, 2001.

[39] A. Minneboo, B. Jasperse, F. Barkhof et al., "Predicting shortterm disability progression in early multiple sclerosis: added value of MRI parameters," Journal of Neurology, Neurosurgery and Psychiatry, vol. 79, no. 8, pp. 917-923, 2008.

[40] Z. Khaleeli, O. Ciccatelli, F. Manfredonia et al., "Predicting progression in primary progressive multiple sclerosis: a 10-year multicenter study," Annals of Neurology, vol. 63, no. 6, pp. 790793, 2008.

[41] V. Popescu, F. Agosta, H. E. Hulst et al., "Brain atrophy and lesion load predict long term disability in multiple sclerosis," Journal of Neurology, Neurosurgery, and Psychiatry, vol. 84, no. 10, pp. 1082-1091, 2013.

[42] B. Jasperse, H. Vrenken, E. Sanz-Arigita et al., "Regional brain atrophy development is related to specific aspects of clinical dysfunction in multiple sclerosis," NeuroImage, vol. 38, no. 3, pp. 529-537, 2007.

[43] J. Sepulcre, J. Sastre-Garriga, M. Cercignani, G. T. Ingle, D. H. Miller, and A. J. Thompson, "Regional gray matter atrophy in early primary progressive multiple sclerosis: a voxel-based morphometry study," Archives of Neurology, vol. 63, no. 8, pp. 1175-1180, 2006.

[44] J. T. Chen, S. Narayanan, D. L. Collins, S. M. Smith, P. M. Matthews, and D. L. Arnold, "Relating neocortical pathology to disability progression in multiple sclerosis using MRI," NeuroImage, vol. 23, no. 3, pp. 1168-1175, 2004.

[45] L. K. Fisniku, D. T. Chard, J. S. Jackson et al., "Gray matter atrophy is related to long-term disability in multiple sclerosis," Annals of Neurology, vol. 64, no. 3, pp. 247-254, 2008.

[46] S. D. Roosendaal, K. Bendfeldt, H. Vrenken et al., "Grey matter volume in a large cohort of MS patients: relation to MRI parameters and disability," Multiple Sclerosis, vol. 17, no. 9, pp. 1098-1106, 2011.

[47] R. A. Rudick, J.-C. Lee, K. Nakamura, and E. Fisher, "Gray matter atrophy correlates with MS disability progression measured with MSFC but not EDSS," Journal of the Neurological Sciences, vol. 282, no. 1-2, pp. 106-111, 2009.

[48] M. Calabrese, C. Romualdi, V. Poretto et al., "The changing clinical course of multiple sclerosis: a matter of grey matter," Annals of Neurology, vol. 74, no. 1, pp. 76-83, 2013.

[49] M. Sailer, B. Fischl, D. Salat et al., "Focal thinning of the cerebral cortex in multiple sclerosis," Brain, vol.126, no. 8, pp. 1734-1744, 2003.

[50] B. Audoin, G. R. Davies, L. Finisku, D. T. Chard, A. J. Thompson, and D. H. Miller, "Localization of grey matter atrophy in early RRMS: a longitudinal study," Journal of Neurology, vol. 253, no. 11, pp. 1495-1501, 2006.

[51] M. Calabrese, M. Atzori, V. Bernardi et al., "Cortical atrophy is relevant in multiple sclerosis at clinical onset," Journal of Neurology, vol. 254, no. 9, pp. 1212-1220, 2007.

[52] R. H. B. Benedict, D. Ramasamy, F. Munschauer, B. WeinstockGuttman, and R. Zivadinov, "Memory impairment in multiple sclerosis: correlation with deep grey matter and mesial temporal atrophy," Journal of Neurology, Neurosurgery and Psychiatry, vol. 80, no. 2, pp. 201-206, 2009.

[53] N. L. Sicotte, K. C. Kern, B. S. Giesser et al., "Regional hippocampal atrophy in multiple sclerosis," Brain, vol. 131, no. 4, pp. 1134-1141, 2008.

[54] M. Calabrese, V. Poretto, A. Favaretto et al., "Cortical lesion load associates with progression of disability in multiple sclerosis," Brain, vol. 135, no. 10, pp. 2952-2961, 2012.

[55] G. J. Lycklama À Nijeholt, M. A. A. van Walderveen, J. A. Castelijns et al., "Brain and spinal cord abnormalities in multiple sclerosis: correlation between MRI parameters, clinical subtypes and symptoms," Brain, vol. 121, no. 4, pp. 687-697, 1998.

[56] N. A. Losseff, S. L. Webb, J. I. O’Riordan et al., "Spinal cord atrophy and disability in multiple sclerosis. A new reproducible and sensitive MRI method with potential to monitor disease progression," Brain, vol. 119, no. 3, pp. 701-708, 1996. 
[57] M. Rovaris, M. Bozzali, G. Santuccio et al., "Relative contributions of brain and cervical cord pathology to multiple sclerosis disability: a study with magnetisation transfer ratio histogram analysis," Journal of Neurology Neurosurgery and Psychiatry, vol. 69, no. 6, pp. 723-727, 2000.

[58] F. Agosta, M. Rovaris, E. Pagani, M. P. Sormani, G. Comi, and M. Filippi, "Magnetization transfer MRI metrics predict the accumulation of disability 8 years later in patients with multiple sclerosis," Brain, vol. 129, no. 10, pp. 2620-2627, 2006.

[59] M. Rovaris, E. Judica, A. Gallo et al., "Grey matter damage predicts the evolution of primary progressive multiple sclerosis at 5 years," Brain, vol. 129, no. 10, pp. 2628-2634, 2006.

[60] M. Calabrese, F. Rinaldi, D. Seppi et al., "Cortical diffusiontensor imaging abnormalities in multiple sclerosis: a 3-year longitudinal study," Radiology, vol. 261, no. 3, pp. 891-898, 2011.

[61] A. Martínez-Yélamos, A. Rovira, R. Sánchez-Valle et al., "CSF 14-3-3 protein assay and MRI as prognostic markers in patients with a clinically isolated syndrome suggestive of MS," Journal of Neurology, vol. 251, no. 10, pp. 1278-1279, 2004.

[62] M. Colucci, L. Roccatagliata, E. Capello et al., "The 14-3-3 protein in multiple sclerosis: a marker of disease severity," Multiple Sclerosis, vol. 10, no. 5, pp. 477-481, 2004.

[63] F. G. Joseph, C. L. Hirst, T. P. Pickersgill, Y. Ben-Shlomo, N. P. Robertson, and N. J. Scolding, "CSF oligoclonal band status informs prognosis in multiple sclerosis: a case control study of 100 patients," Journal of Neurology, Neurosurgery and Psychiatry, vol. 80, no. 3, pp. 292-296, 2009.

[64] N. Norgren, P. Sundström, A. Svenningsson, L. Rosengren, T. Stigbrand, and M. Gunnarsson, "Neurofilament and glial fibrillary acidic protein in multiple sclerosis," Neurology, vol. 63, no. 9, pp. 1586-1590, 2004.

[65] J. Salzer, A. Svenningsson, and P. Sundström, "Neurofilament light as a prognostic marker in multiple sclerosis," Multiple Sclerosis, vol. 16, no. 3, pp. 287-292, 2010.

[66] A. Petzold, M. J. Eikelenboom, G. Keir et al., "Axonal damage accumulates in the progressive phase of multiple sclerosis: three year follow up study," Journal of Neurology, Neurosurgery and Psychiatry, vol. 76, no. 2, pp. 206-211, 2005.

[67] K. Rejdak, A. Petzold, Z. Stelmasiak, and G. Giovannoni, "Cerebrospinal fluid brain specific proteins in relation to nitric oxide metabolites during relapse of multiple sclerosis," Multiple Sclerosis, vol. 14, no. 1, pp. 59-66, 2008.

[68] L. M. Villar, N. García-Barragán, M. Espiño et al., "Influence of oligoclonal IgM specificity in multiple sclerosis disease course," Multiple Sclerosis, vol. 14, no. 2, pp. 183-187, 2008.

[69] J. Mandrioli, P. Sola, R. Bedin, M. Gambini, and E. Merelli, "A multifactorial prognostic index in multiple sclerosis: cerebrospinal fluid IgM oligoclonal bands and clinical features to predict the evolution of the disease," Journal of Neurology, vol. 255, no. 7, pp. 1023-1031, 2008.

[70] M. Comabella, M. Fernández, R. Martin et al., "Cerebrospinal fluid chitinase 3-like 1 levels are associated with conversion to multiple sclerosis," Brain, vol. 133, no. 4, pp. 1082-1093, 2010.

[71] A. Gajofatto, S. Monaco, M. Fiorini et al., "Assessment of outcome predictors in first-episode acute myelitis a retrospective study of 53 cases," Archives of Neurology, vol. 67, no. 6, pp. 724730, 2010.

[72] H. Tremlett, Y. Zhao, P. Rieckmann, and M. Hutchinson, "New perspectives in the natural history of multiple sclerosis," Neurology, vol. 74, no. 24, pp. 2004-2015, 2010.
[73] A. Gajofatto, M. Bongianni, G. Zanusso et al., "Clinical and biomarker assessment of demyelinating events suggesting multiple sclerosis," Acta Neurologica Scandinavica, vol. 128, no. 5, pp. 336-344, 2013.

[74] A. E. Hensiek, S. R. Seaman, L. F. Barcellos et al., "Familial effects on the clinical course of multiple sclerosis," Neurology, vol. 68, no. 5, pp. 376-383, 2007.

[75] C. Confavreux and S. Vukusic, "Age at disability milestones in multiple sclerosis," Brain, vol. 129, no. 3, pp. 595-605, 2006.

[76] C. Renoux, S. Vukusic, Y. Mikaeloff et al., "Natural history of multiple sclerosis with childhood onset," The New England Journal of Medicine, vol. 356, no. 25, pp. 2603-2613, 2007.

[77] M. Tutuncu, J. Tang, N. A. Zeid et al., "Onset of progressive phase is an age-dependent clinical milestone in multiple sclerosis," Multiple Sclerosis, vol. 19, no. 2, pp. 188-198, 2013.

[78] A. Scalfari, A. Neuhaus, A. Degenhardt et al., "The natural history of multiple sclerosis, a geographically based study 10 : relapses and long-term disability," Brain, vol. 133, no. 7, pp. 19141929, 2010.

[79] M. Hutchinson, "Truly benign multiple sclerosis is rare: Let's stop fooling ourselves-commentary," Multiple Sclerosis, vol. 18, no. 1, p. 15, 2012.

[80] J. F. Kurtzke, "Rating neurologic impairment in multiple sclerosis: an Expanded Disability Status Scale (EDSS)," Neurology, vol. 33, no. 11, pp. 1444-1452, 1983.

[81] F. D. Lublin and S. C. Reingold, "Defining the clinical course of multiple sclerosis: results of an international survey," Neurology, vol. 46, no. 4, pp. 907-911, 1996.

[82] S. J. Pittock, R. L. McClelland, W. T. Mayr et al., "Clinical implications of benign multiple sclerosis: a 20 -year populationbased follow-up study," Annals of Neurology, vol. 56, no. 2, pp. 303-306, 2004.

[83] M. P. Amato, E. Portaccio, M. L. Stromillo et al., "Cognitive assessment and quantitative magnetic resonance metrics can help to identify benign multiple sclerosis," Neurology, vol. 71, no. 9, pp. 632-638, 2008.

[84] A.-L. Sayao, V. Devonshire, and H. Tremlett, "Longitudinal follow-up of "benign" multiple sclerosis at 20 years," Neurology, vol. 68, no. 7, pp. 496-500, 2007.

[85] G. S. M. Ramsaransing and J. de Keyser, "Predictive value of clinical characteristics for "benign" multiple sclerosis," European Journal of Neurology, vol. 14, no. 8, pp. 885-889, 2007.

[86] E. Leray, M. Coustans, E. Le Page, J. Yaouanq, J. Oger, and G. Edan, "'Clinically definite benign multiple sclerosis', an unwarranted conceptual hodgepodge: evidence from a 30-year observational study," Multiple Sclerosis, vol. 19, no. 4, pp. 458465, 2013.

[87] L. Costelloe, A. Thompson, C. Walsh, N. Tubridy, and M. Hutchinson, "Long-term clinical relevance of criteria for designating multiple sclerosis as benign after 10 years of disease," Journal of Neurology, Neurosurgery and Psychiatry, vol. 79, no. 11, pp. 1245-1248, 2008.

[88] P. O'Connor, P. Marchetti, L. Lee, and M. Perera, "Evoked potential abnormality scores are a useful measure of disease burden in relapsing-remitting multiple sclerosis," Annals of Neurology, vol. 44, no. 3, pp. 404-407, 1998.

[89] P. Fuhr, A. Borggrefe-Chappuis, C. Schindler, and L. Kappos, "Visual and motor evoked potentials in the course of multiple sclerosis," Brain, vol. 124, no. 11, pp. 2162-2168, 2001.

[90] L. Leocani, M. Rovaris, F. M. Boneschi et al., "Multimodal evoked potentials to assess the evolution of multiple sclerosis: 
a longitudinal study," Journal of Neurology, Neurosurgery and Psychiatry, vol. 77, no. 9, pp. 1030-1035, 2006.

[91] B. A. Kallmann, S. Fackelmann, K. V. Toyka, P. Rieckmann, and K. Reiners, "Early abnormalities of evoked potentials and future disability in patients with multiple sclerosis," Multiple Sclerosis, vol. 12, no. 1, pp. 58-65, 2006.

[92] P. Invernizzi, L. Bertolasi, M. R. Bianchi, M. Turatti, A. Gajofatto, and M. D. Benedetti, "Prognostic value of multimodal evoked potentials in multiple sclerosis: the EP score," Journal of Neurology, vol. 258, no. 11, pp. 1933-1939, 2011.

[93] R. Schlaeger, M. D’Souza, C. Schindler et al., "Prediction of long-term disability in multiple sclerosis," Multiple Sclerosis, vol. 18, no. 1, pp. 31-38, 2012.

[94] R. Pelayo, X. Montalban, T. Minoves et al., "Do multimodal evoked potentials add information to MRI in clinically isolated syndromes?” Multiple Sclerosis, vol. 16, no. 1, pp. 55-61, 2010.

[95] A. Petzold, J. F. de Boer, S. Schippling et al., "Optical coherence tomography in multiple sclerosis: a systematic review and metaanalysis," The Lancet Neurology, vol. 9, no. 9, pp. 921-932, 2010.

[96] K. L. Young, A. U. Brandt, A. Petzold et al., "Loss of retinal nerve fibre layer axons indicates white but not grey matter damage in early multiple sclerosis," European Journal of Neurology, vol. 20, no. 5, pp. 803-811, 2013.

[97] J. N. Ratchford, S. Saidha, E. S. Sotirchos et al., "Active MS is associated with accelerated retinal ganglion cell/inner plexiform layer thinning," Neurology, vol. 80, no. 1, pp. 47-54, 2013.

[98] S. Saidha, S. B. Syc, M. A. Ibrahim et al., "Primary retinal pathology in multiple sclerosis as detected by optical coherence tomography," Brain, vol. 134, no. 2, pp. 518-533, 2011.

[99] P. Albrecht, M. Ringelstein, A. K. Müller et al., "Degeneration of retinal layers in multiple sclerosis subtypes quantified by optical coherence tomography," Multiple Sclerosis, vol. 18, no. 10, pp. 1422-1429, 2012.

[100] F. Fazekas, P. Soelberg-Sorensen, G. Comi, and M. Filippi, "MRI to monitor treatment efficacy in multiple sclerosis," Journal of Neuroimaging, vol. 17, supplement s1, pp. 50S-55S, 2007.

[101] P. A. Brex, O. Ciccarelli, J. I. O’Riordan, M. Sailer, A. J. Thompson, and D. H. Miller, "A longitudinal study of abnormalities on MRI and disability from multiple sclerosis," The New England Journal of Medicine, vol. 346, no. 3, pp. 158-164, 2002.

[102] M. Filippi, M. A. Horsfield, S. P. Morrissey et al., "Quantitative brain MRI lesion load predicts the course of clinically isolated syndromes suggestive of multiple sclerosis," Neurology, vol. 44, no. 4, pp. 635-641, 1994.

[103] F. Pérez-Miralles, J. Sastre-Garriga, M. Tintoré et al., "Clinical impact of early brain atrophy in clinically isolated syndromes," Multiple Sclerosis, 2013.

[104] M. A. Rocca, S. Mesaros, E. Pagani, M. P. Sormani, G. Comi, and M. Filippi, "Thalamic damage and long-term progression of disability in multiple sclerosis," Radiology, vol. 257, no. 2, pp. 463-469, 2010.

[105] A. Kutzelnigg, J. C. Faber-Rod, J. Bauer et al., "Widespread demyelination in the cerebellar cortex in multiple sclerosis," Brain Pathology, vol. 17, no. 1, pp. 38-44, 2007.

[106] M. Calabrese, I. Mattisi, F. Rinaldi et al., "Magnetic resonance evidence of cerebellar cortical pathology in multiple sclerosis," Journal of Neurology, Neurosurgery and Psychiatry, vol. 81, no. 4, pp. 401-404, 2010.

[107] M. Calabrese, P. Grossi, A. Favaretto et al., "Cortical pathology in multiple sclerosis patients with epilepsy: a 3 year longitudinal study," Journal of Neurology, Neurosurgery and Psychiatry, vol. 83, no. 1, pp. 49-54, 2012.
[108] G. Lycklama, A. Thompson, M. Filippi et al., "Spinal-cord MRI in multiple sclerosis," The Lancet Neurology, vol. 2, no. 9, pp. 555-562, 2003.

[109] F. Agosta, M. Absinta, M. P. Sormani et al., "In vivo assessment of cervical cord damage in MS patients: a longitudinal diffusion tensor MRI study," Brain, vol. 130, no. 8, pp. 2211-2219, 2007.

[110] A. Martínez-Yélamos, A. Saiz, J. Bas, J. J. Hernandez, F. Graus, and T. Arbizu, "Tau protein in cerebrospinal fluid: a possible marker of poor outcome in patients with early relapsingremitting multiple sclerosis," Neuroscience Letters, vol. 363, no. 1, pp. 14-17, 2004.

[111] J. Brettschneider, H. Tumani, U. Kiechle et al., "IgG antibodies against measles, rubella, and varicella zoster virus predict conversion to multiple sclerosis in clinically isolated syndrome," PLoS ONE, vol. 4, no. 11, Article ID e7638, 2009.

[112] M. Khademi, I. Kockum, M. L. Andersson et al., "Cerebrospinal fluid CXCL13 in multiple sclerosis: a suggestive prognostic marker for the disease course," Multiple Sclerosis, vol. 17, no. 3, pp. 335-343, 2011.

[113] C. E. Teunissen, P. C. Dijkstra, and C. Polman, "Biological markers in CSF and blood for axonal degeneration in multiple sclerosis," The Lancet Neurology, vol. 4, no. 1, pp. 32-41, 2005.

[114] A. Gajofatto, M. Bongianni, G. Zanusso, M. D. Benedetti, and S. Monaco, "Are cerebrospinal fluid biomarkers useful in predicting the prognosis of multiple sclerosis patients?" International Journal of Molecular Sciences, vol. 12, no. 11, pp. 7960-7970, 2011.

[115] E. Kapaki, G. P. Paraskevas, M. Michalopoulou, and K. Kilidireas, "Increased cerebrospinal fluid tau protein in multiple sclerosis," European Neurology, vol. 43, no. 4, pp. 228-232, 2000.

[116] H. Bartosik-Psujek and J. J. Archelos, “Tau protein and 14-3-3 are elevated in the cerebrospinal fluid of patients with multiple sclerosis and correlate with intrathecal synthesis of IgG," Journal of Neurology, vol. 251, no. 4, pp. 414-420, 2004.

[117] J. Brettschneider, M. Maier, S. Arda et al., "Tau protein level in cerebrospinal fluid is increased in patients with early multiple sclerosis," Multiple Sclerosis, vol. 11, no. 3, pp. 261-265, 2005.

[118] M. Terzi, A. Birinci, E. Çetinkaya, and M. K. Onar, "Cerebrospinal fluid total tau protein levels in patients with multiple sclerosis," Acta Neurologica Scandinavica, vol. 115, no. 5, pp. 325330, 2007.

[119] J. Frederiksen, K. Kristensen, J. M. C. Bahl, and M. Christiansen, "Tau protein: a possible prognostic factor in optic neuritis and multiple sclerosis," Multiple Sclerosis, vol. 18, no. 5, pp. 592-599, 2012.

[120] F. J. Jiménez-Jiménez, J. M. Zurdo, A. Hernanz et al., “Tau protein concentrations in cerebrospinal fluid of patients with multiple sclerosis," Acta Neurologica Scandinavica, vol. 106, no. 6, pp. 351-354, 2002.

[121] J. Guimarães, M. J. Cardoso, and M. J. Sá, “Tau protein seems not to be a useful routine clinical marker of axonal damage in multiple sclerosis," Multiple Sclerosis, vol. 12, no. 3, pp. 354-356, 2006.

[122] C. E. Teunissen, E. Tacobaeus, M. Khademi et al., "Combination of CSF N-acetylaspartate and neurofilaments in multiple sclerosis," Neurology, vol. 72, no. 15, pp. 1322-1329, 2009.

[123] M. Fiorini, G. Zanusso, M. D. Benedetti, P. G. Righetti, and S. Monaco, "Cerebrospinal fluid biomarkers in clinically isolated syndromes and multiple sclerosis," Proteomics, vol. 1, no. 9, pp. 963-971, 2007. 
[124] J. Jaworski, M. Psujek, M. Janczarek, M. Szczerbo-Trojanowska, and H. Bartosik-Psujek, "Total-tau in cerebrospinal fluid of patients with multiple sclerosis decreases in secondary progressive stage of disease and reflects degree of brain atrophy," Upsala Journal of Medical Sciences, vol. 117, no. 3, pp. 284-292, 2012.

[125] N. de Stefano, A. Giorgio, M. Battaglini et al., "Assessing brain atrophy rates in a large population of untreated multiple sclerosis subtypes," Neurology, vol. 74, no. 23, pp. 1868-1876, 2010.

[126] J. de Seze, K. Peoc'h, D. Ferriby, T. Stojkovic, J.-L. Laplanche, and P. Vermersch, "14-3-3 protein in the cerebrospinal fluid of patients with acute transverse myelitis and multiple sclerosis," Journal of Neurology, vol. 249, no. 5, pp. 626-627, 2002.

[127] K. Hein (née Maier), A. Köhler, R. Diem et al., "Biological markers for axonal degeneration in CSF and blood of patients with the first event indicative for multiple sclerosis," Neuroscience Letters, vol. 436, no. 1, pp. 72-76, 2008.

[128] C. Malmeström, S. Haghighi, L. Rosengren, O. Andersen, and J. Lycke, "Neurofilament light protein and glial fibrillary acidic protein as biological markers in MS," Neurology, vol. 61, no. 12, pp. 1720-1725, 2003.

[129] J. Kuhle, D. Leppert, A. Petzold et al., "Neurofilament heavy chain in CSF correlates with relapses and disability in multiple sclerosis," Neurology, vol. 76, no. 14, pp. 1206-1213, 2011.

[130] M. Khalil, C. Enzinger, C. Langkammer et al., "CSF neurofilament and $\mathrm{N}$-acetylaspartate related brain changes in clinically isolated syndrome," Multiple Sclerosis, vol. 19, no. 4, pp. 436442, 2013.

[131] B. Bielekova and R. Martin, "Development of biomarkers in multiple sclerosis," Brain, vol. 127, no. 7, pp. 1463-1478, 2004.

[132] C. E. Teunissen, A. Petzold, J. L. Bennett et al., "A consensus protocol for the standardization of cerebrospinal fluid collection and biobanking," Neurology, vol. 73, no. 22, pp. 1914-1922, 2009.

[133] C. Teunissen, T. Menge, A. Altintas et al., "Consensus definitions and application guidelines for control groups in cerebrospinal fluid biomarker studies in multiple sclerosis," Multiple Sclerosis, 2013. 


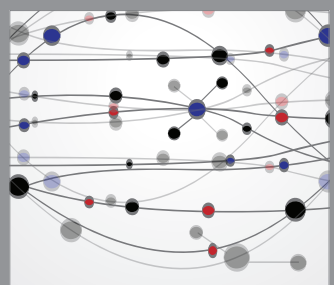

The Scientific World Journal
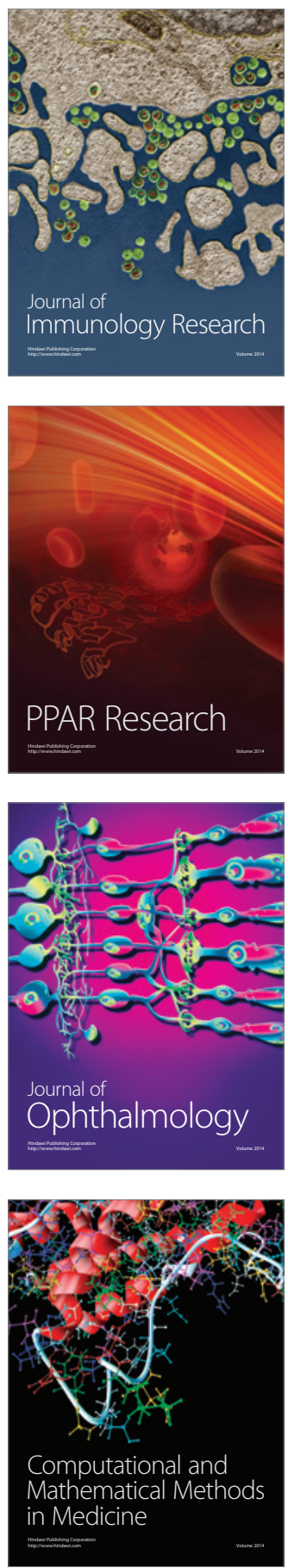

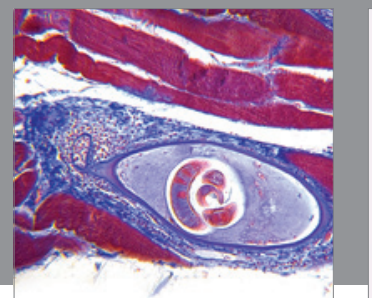

Gastroenterology

Research and Practice
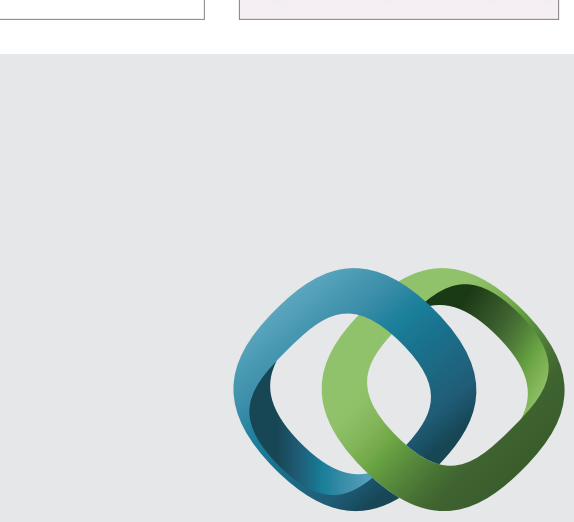

\section{Hindawi}

Submit your manuscripts at

http://www.hindawi.com
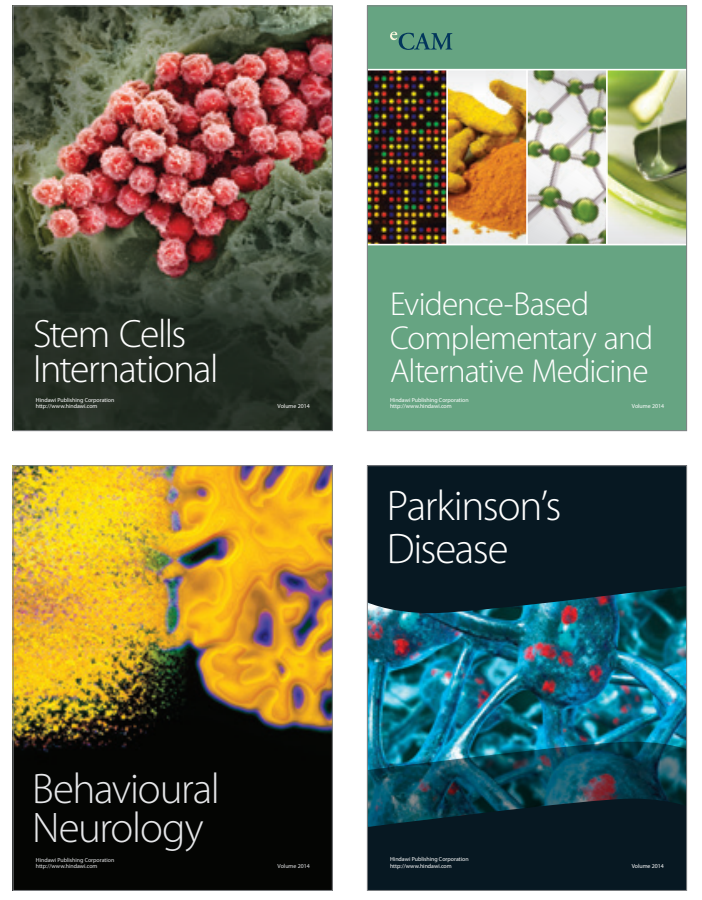
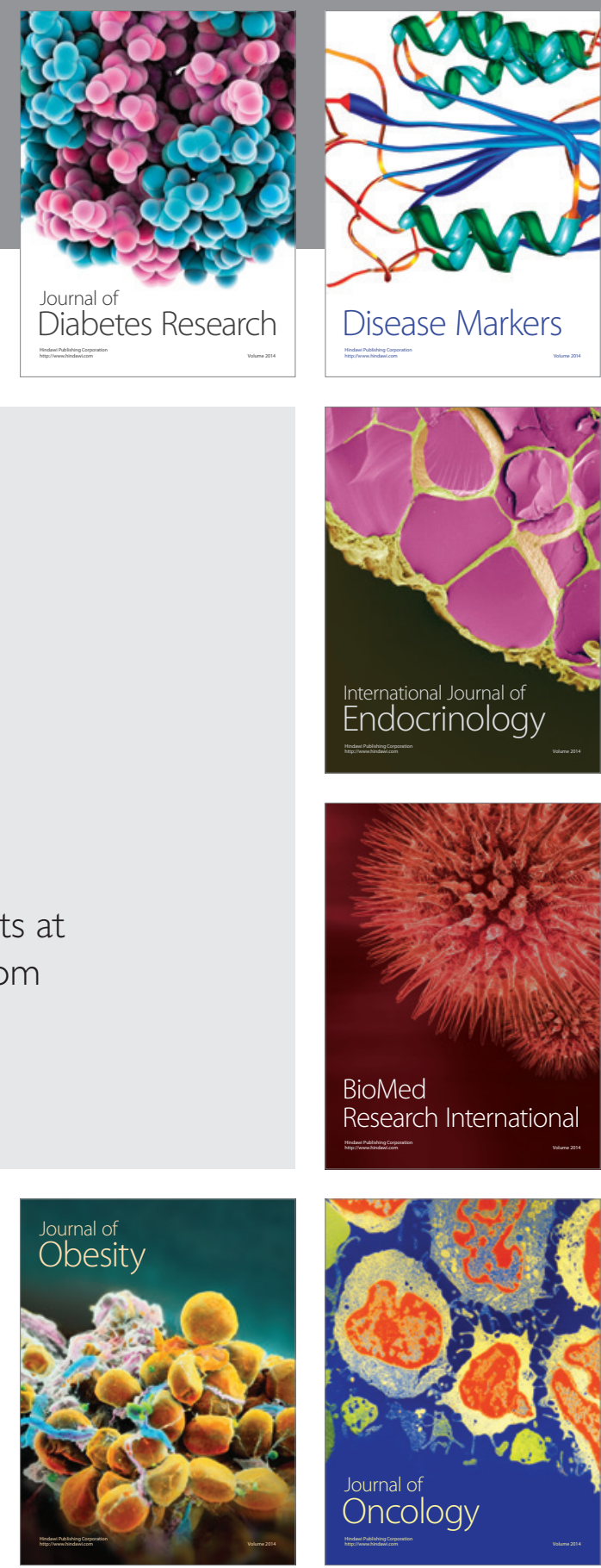

Disease Markers
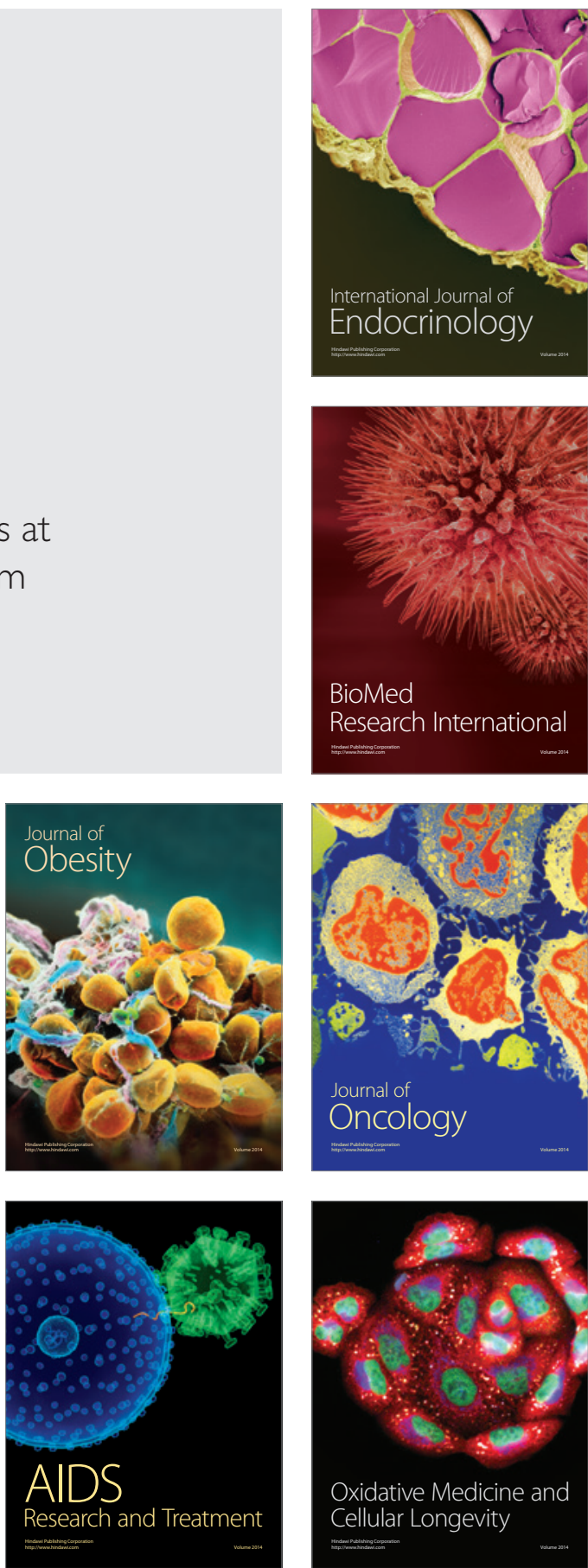